MOVERS

\section{Robert Sterner, director, Division of Environmental Biology, National Science Foundation, Washington DC}

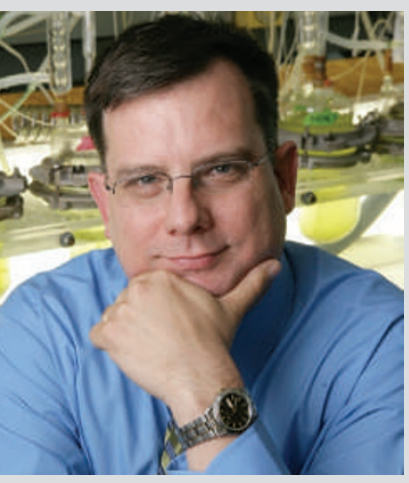

1994-present: Associate to full professor, University of Minnesota, St Paul 1999-2003: Head of ecology, evolution and behaviour department, University of Minnesota, St Paul 1988-94: Assistant to associate professor, University of Texas at Arlington

Robert Sterner's first visit to the rocky coast of Maine instilled a lifelong fascination with the layering and distributions of aquatic organisms - leaving no question that he would specialize in ecology as a biology undergraduate at the University of Illinois.

The future limnologist studied zooplankton interactions as a PhD student at the University of Minnesota to help answer a puzzling question: could ecological effects between two species be measured across food webs? His work showed that the indirect effects of zooplankton eating algae - such as nutrient recycling - were at least as important to population dynamics as direct consumption.

Sterner says his excellent conceptual and theoretical training at Minnesota was matched by the experimental skill he encountered as a postdoc at the Max Planck Institute for Limnology in Plön, Germany. "I had never witnessed work being done at the scale or rigour being done there," he says.

As an associate professor at the University of Texas at Arlington, Sterner received his first National Science Foundation (NSF) grant and stumbled upon an unexpected finding - that the nutrient content of algae determines how fast the herbivores that feed on them grow. He and his close colleague Jim Elser then, literally, wrote the book on quantitative nutrient relationships, otherwise known as ecological stoichiometry.

An unexpected opportunity at a research institute brought Sterner back to Minnesota as a professor. Five years later he was department head, but ultimately returned after four years to his first love: research.

In July, he will temporarily leave his own lab to provide direction for ecological research funding as director of NSF's Division of Environmental Biology, the largest US federal funder of ecological and environmental biology research. With climate change increasingly prominent on the political agenda, Sterner says it's important to demonstrate that environmental biology is a big part of global change research. "The public may not think of it in these terms, but they care whether ecosystems remain intact," he says.

Alan Tessier, acting deputy director for the division, likes the way that Sterner's research has ranged from evolution to ecosystem questions in freshwater and oceans. Sterner's broad background, says Tessier, gives him the perspective necessary to make interdisciplinary linkages, especially as ecology transforms into a more quantitative science. Virginia Gewin

\section{NETWORKS \& SUPPORT}

\section{Fountain of funding for youth}

Last month, the California Institute for Regenerative Medicine (CIRM), an upstart state-funded initiative to make California a stem-cell research hub, announced plans to award $\$ 85$ million to 25 young scientists. It's an effort to help fledgling investigators who often have a tough time finding start-up funds.

Like the institute's previous grants, these CIRM grants include funding for research on human embryonic stemcells, which is severely restricted under US federal funding policy. That policy has prevented scientists from entering the field, says Christopher Scott, executive director of the Stem Cells and Society Program at Stanford University, California. He believes that CIRM's grants should help stem-cell scientists feel less obliged to study related but less controversial fields.

US biomedics moving from postdoc to independent research often struggle to find stable sources of funding. New investigators receive only $6 \%$ of US National Institutes of Health (NIH) R01 awards, the multi-year grants that US universities rely on. Similar to R01, the CIRM grants will fund direct project costs of $\$ 300,000$ for academics and $\$ 400,000$ for clinicians. Worries over money hamper long-term thinking, says Xianmin Zeng of the Buck
Institute in Novato, California, who plans to apply. Many foundations give only small amounts of money over one or two years, she says. "For young investigators to get a stable environment, they need a stable foundation," Zeng says.

Although previous CIRM grants targeted research in human are broader in scope. Researchers working on animal systems as well as on non-embryonic systems are eligible. But the grants are also intended to push basic research into clinical applications. Ten of the 25 slots are reserved for physician researchers. "They are critical to translating this research into therapies," says the CIRM's scientific officer, Kumar Hari.

Courting some controversy, the CIRM has restricted the number of candidates qualifying institutions can nominate. Organizations with medical schools can nominate four faculty members; those without can nominate two. Otherwise, say CIRM officials, the awards might attract hundreds of applicants and overwhelm staff and outside reviewers. Candidates must submit letters of intent by 9 August this year.

Monya Baker is the editor of Nature Reports Stem Cells. embryonic stem cells, the new grants

\section{POSTDOC JOURNAL}

\section{Vision}

Microscopy is an important component of some of my experiments, and it's a fitting analogy for how l've viewed my postdoctoral training. At first, l look with almost child-like awe at what lies before me under the microscope. As always, there's that small joy at the instant when the plane comes into sharp focus, and everything becomes clear. But after observing and analysing hundreds of cells, my eyes grow tired, and so do I. My sense of wonder is replaced by weariness, and it's difficult to see past the next undertaking. Sometimes, when faced with routine tasks, it can be easy to become blind to the opportunities and to lose sight of the big picture.

This, I've learned, is a good time to take a short break and to refocus. Reflecting on almost two years of being a postdoc, I realize the importance of having a balanced outlook. Like changing a lens, examining a situation with fresh eyes often reveals a different perspective. With another look or upon closer inspection, new insights become apparent and additional possibilities emerge. As the saying goes: "When you change how you look at things, the things you look at change." As I consider my postdoctoral research goals, I try to remind myself of this adage. After all, in a scientific career, as with microscopy, there's simply no progress without a clear vision.

Maria Thelma Ocampo-Hafalla is a research fellow at Cancer Research UK's London Research Institute. 